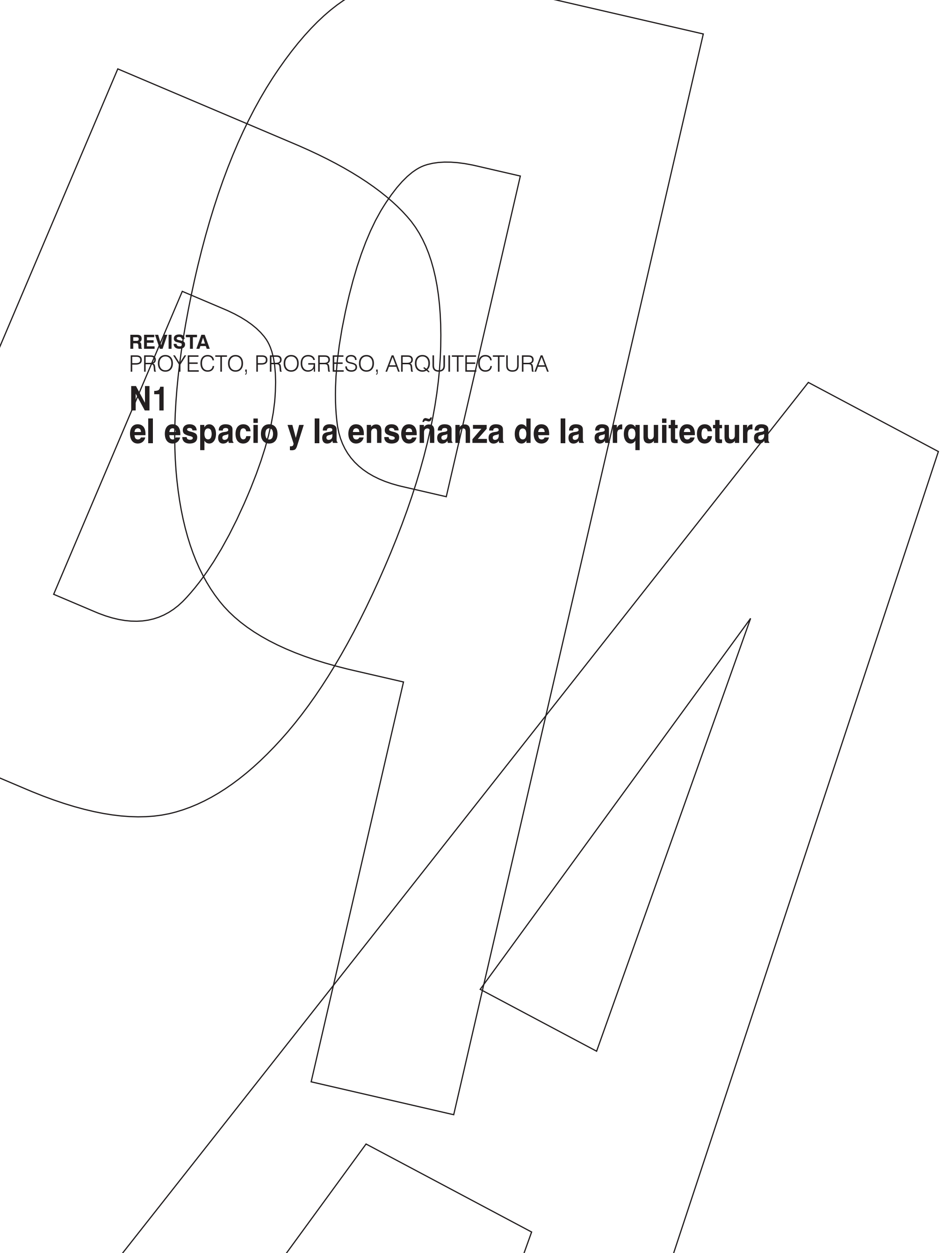




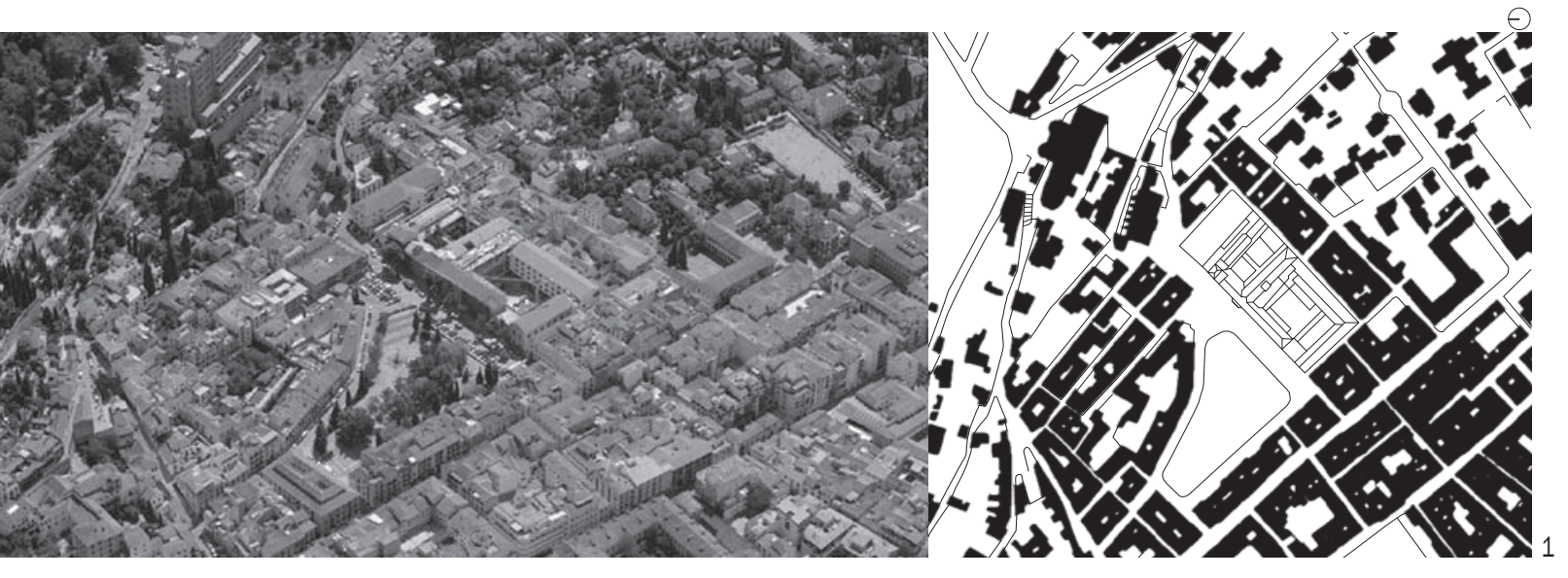

RESUMEN En el corazón de Granada, la nueva Escuela de Arquitectura se instala sobre las preexistencias del antiguo Hospital Militar, situado en el barrio del Realejo. El edificio que se adecua a espacio docente suma así un nuevo eslabón en la cadena de transformaciones que, desde preexistencias del periodo nazarí, han ido conformando mediante adiciones, transformaciones y cambios de uso, un conjunto arquitectónico que es reinterpretado por el proyecto y la posterior ejecución de la obra. En su actuación y aprovechando el desnivel topográfico, la sección arquitectónica toma el mando a la hora de dotar al conjunto de una idea integradora: a través de ella se produce la localización de los programas para conseguir una lectura de las diversas escalas del edificio, atenta especialmente a los patios, claustros, galerías y zaguanes y a sus concatenaciones, así como a la captación de la luz a través de diversos recursos cenitales. El proceso constructivo descubre la estructura de muros y el artesonado de los techos, recuperándose desde clave contemporánea, aquellos que resultan ser preexistencias ejemplares. Ambos recursos -luz cenital y espacios abiertos- se reúnen en la adición subterránea del Aula Magna, en el que la evocación a la excavación arqueológica y el silencio de la concentración cohabitan con el bullicio estudiantil del patio liberado sobre él.

PALABRAS CLAVE Granada, escuelas de arquitectura, espacio docente, intervención en el patrimonio, claustro, luz cenital.

SUMMARY In the heart of Granada, the new School of Architecture is housed in the old, converted, Military Hospital, located in the Realejo district. The new adaption of the building to an educational space adds a new link to the chain of transformations by which old structures have been reshaped by means of additions, transformations and changes of use since the Nazari period. An architectural whole that is reinterpreted by the plan and the later execution of the work. Making use of the topographical unevenness, the developing architectural section takes control by providing one integrating idea for the whole. It locates programmes for an interpretation of the diverse scales of the building, with special attention to the patios, cloisters, galleries and halls and their concatenations, as well as to the capture of light through various zenithal resources. The construction process uncovers the structure of walls and the coffering of the ceilings, recovering exemplary older structures from contemporary cover. The resources of both zenithal light and open spaces are united in the underground addition of the main lecture hall, in which the evocation of archaeological excavation and the silence of concentration coexist with the student hubbub of the liberated patio above it.

KEY WORDS Granada, architecture schools, educational space, heritage intervention, cloister, zenithal light. 


\section{REHABILITACION DEL ANTIGUO HOSPITAL MILITAR DE GRANADA PARA NUEVA ESCUELA DE ARQUITECTURA}

TRANSFORMATION OF THE OLD MILITARY HOSPITAL OF GRANADA INTO THE NEW SCHOOL OF ARCHITECTURE

Víctor López Cotelo

CIUDAD Y PREEXISTENCIA: EL ANTIGUO HOSPITAL MILITAR

I edificio se encuentra situado en el barrio $\mathrm{E}$ del Realejo, (antigua Antequeruela) en el extremo sudeste del casco histórico de Granada, al pie de la ladera del Mauror (paralela a la Sabika de la Alhambra). Su nuevo uso docente universitario, tras su pasado como hospital militar, se adscribe claramente a la opción urbana de la Universidad de Granada de mantener y rehabilitar edificios emblemáticos dentro del centro histórico como campus frente a anteriores estrategias descentralizadoras o periféricas.

El edificio presenta un amplio frente al Campo del Príncipe, un importante espacio urbano de origen renacentista, y las restantes fachadas se insertan en las estrechas calles del tejido urbano del barrio circundante, donde solo destaca la iglesia de San Cecilio (figura 1). En el lindero nordeste se ha segregado una parte del antiguo edificio que mantiene el uso sanitario militar anterior. El desnivel topográfico de esta amplia manzana (seis metros entre NE y SO) se resuelve en su interior mediante un patio en dos niveles en el extremo SO.

Se parte reconociendo un conjunto de edificios que finalmente han conformado una gran manzana urbana que supera en tamaño las pequeñas dimensiones morfológicas de las manzanas circundantes. La consolidación de este complejo aditivo, es consecuencia de un dilatado proceso de transformación que comenzó con la posible existencia de una casa nazarí, cuyos restos no están totalmente identificados, y siguió con la construcción de la "Casa del Almirante", palacio de dos cuerpos en "L" del siglo XVI de estilo renacentista alrededor de un patio de dos plantas con salones artesonados (figura 2).

Posteriormente el edificio pasó a ser Junta de Comercio, Convento de la Encarnación (con la posible creación de la capilla en 1777) y Escuela Nacional. En 1868 se convirtió en Hospital Militar, añadiéndose una serie de pabellones que eliminan el huerto trasero, doblando el patio original, repetido miméticamente. A la vez, por la parte sur, se van demoliendo edificaciones residenciales adosadas y la manzana trasera, ocupando incluso calles en codo existentes, (Calles de la Reja, del Caño y Socia) construyendo pabellones perimetrales para terminar consolidando una maciza manzana rectangular con fachada parcialmente homogénea al Campo del Príncipe. Para su adaptación provisional como Escuela de Arquitectura se ha demolido un pabellón hospitalario, creando un segundo gran patio y se ha transformado otro de los pabellones adosándole dos columnas de escaleras en su fachada interior. Con ello queda reforzada esta aparente organización tipológica de gran edificio público y monumental con fachada a espacio público representativo y dos grandes patios interiores.

El edificio fue catalogado en su conjunto por el Plan General de Ordenación Urbana del año 1985 con el nivel de protección máximo. Más tarde el Plan Especial del Centro Histórico estableció una catalogación más ajustada a las especiales características de los edificios que componen el conjunto con diversos niveles de protección, aunque todavía sería preciso ajustarla aún más ya que el designado a la zona trasera de la Casa del Almirante no alcanza tal valor histórico. La nueva revisión del Plan General acometida en 1994 y del Plan Especial del Centro Histórico (Sacromonte, Albaicín, Centro, Alhambra) propone en cualquier caso la supresión de estos niveles y su sustitución de acuerdo con la legislación nacional y andaluza de Patrimonio, en tres: Interés Cultural, Arquitectónico y Urbanistico-Ambiental que permitirían catalogar con más precisión el actual edificio y su transformación a Escuela de Arquitectura valorando sobre todo su inserción en el contexto urbano. 
Palacio de los Memdoza. Siglo XVI Planta baja

Hospital Militar 1877 Planta baja

Hospital Militar 1992 Planta primera

Adaptación a ETSA, 1994 Planta baja

Proyecto ETSA Granada, 2003 Planta baja
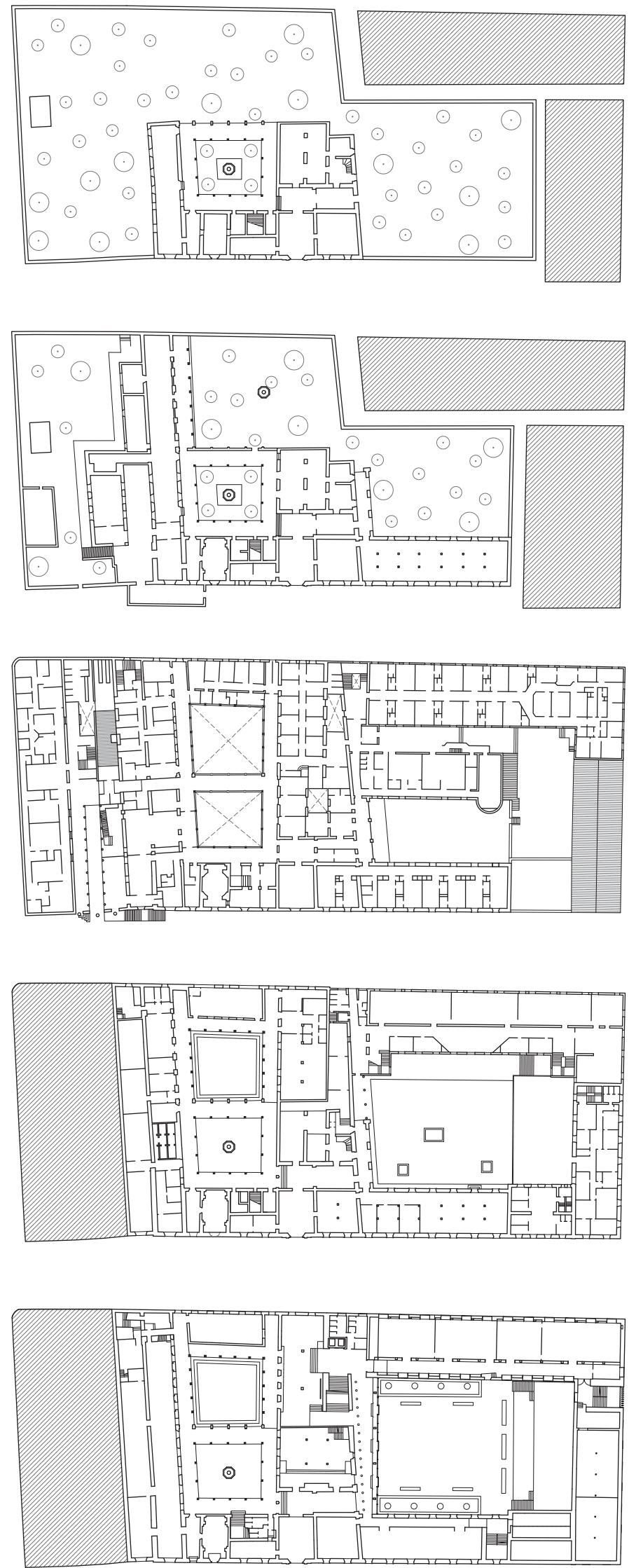

2. Planimetrías del estado original y desarrollo histórico: Casa Nazarí, Casa del Almirante, Hospital Militar y últimas intervenciones del siglo XX.

$$
\begin{array}{lllll}
0 & 5 & 10 & 20 & 50
\end{array}
$$




\section{PROYECTO E INTEGRACIÓN}

El desarrollo aditivo que caracteriza el crecimiento del conjunto desde la primera casa nazarí hasta nuestros días toca a su fin una vez alcanzada la frontera máxima de expansión determinada por los límites de la manzana. Este desarrollo aditivo no ha impedido además, con el paso del tiempo, la colonización invasora de todo aquel espacio susceptible de ser fragmentado, parasitado y abusado por un pragmatismo de corto alcance que ha llegado a privar al conjunto de una mínima inteligencia que articule su estructura.

Afortunadamente, la nueva función asignada como Escuela de Arquitectura exige una intervención clarificadora para alcanzar una unidad, no en sentido estilístico, sino integrador. En este caso, se trata de comprender las potencialidades existentes para que, sinérgicamente, todas ellas alcancen su mejor expresión, aportando del pasado su esencia arquitectónica más auténtica.

Esta autenticidad de las partes será, en esta nueva etapa, el agente catalizador de un nuevo "todo" aglutinado en torno a su nueva función. Nada mejor que una Escuela de Arquitectura que reconozca en la construcción y materialidad de cada época la expresión de su verdadera tarea. iQue la materia, la construcción y la luz sean los agentes integradores del proceso histórico! Nosotros sólo estimularemos el proceso de regeneración que haga que las cosas ocupen el lugar que les corresponde para mejor rendir el fruto arquitectónico para el que fueron creadas. No se trata de inventar nada, sino sólo de comprender de nuevo lo que las cosas siempre fueron aunque no estuvieran debidamente valoradas, añadiendo las estrictamente necesarias para su funcionamiento y eliminando las manifiestamente inapropiadas.

Bien es cierto que en este complejo, junto a elementos que tienen sus propios valores arquitectónicos, hay otros que carecen por el momento de ellos. La actuación pretende precisamente que la tensión arquitectónica que aparezca entre lo "auténtico" del pasado y lo "nuevo" de nuestro presente, impregne y magnetice al resto, de modo que sin sufrir grandes transformaciones, sí encuentre al fin un destino arquitectónico. Para ello habrán de ponerse en valor sus carencias, para que el único valor real que tienen pase sin enmascaramiento alguno a formar parte del nuevo todo.
Esta actuación no será con certeza la última de su historia, por lo que deberá dotar al conjunto de aquellas estructuras mínimas necesarias para que la función encuentre su mejor acomodo en cada momento. Se propone una clarificación de la estructura del edificio, dotándolo de un sistema de circulación-comunicación adecuado a su función universitaria, en el que las distintas etapas de su historia encuentren su expresión, sin que ello suponga fragmentación sino integración y en la que la sencillez constructiva y material sea el soporte de sus valores arquitectónicos peculiares.

Sus zaguanes, patios, galerías, corredores y escaleras son espacios que comunican las distintas partes del edificio pero también los distintos tiempos de su existencia, así como las distintas actividades que se desarrollan en el mismo. Todo esto junto con la diversidad material, constructiva y espacial de sus partes será determinante para identificar de manera reconocible el carácter de esta nueva Escuela de Arquitectura.

\section{REHABILITACIÓN ESTRUCTURAL PARA CONJUGAR CONSERVACIÓN Y OBRA NUEVA}

En la actualidad el edificio como agregado de cuerpos de distinto valor histórico y arquitectónico solo constituye una unidad como elemento urbano.

El proyecto trata de identificar las carencias esenciales del conjunto, aportando los elementos que lo articulen como un todo complejo, en el que cada parte recupere su valor esencial arquitectónico, encontrando una correspondencia material, constructiva y formal que le hagan susceptible de soportar con la máxima flexibilidad un determinado orden funcional.

Desde el punto de vista tipológico el edificio ha encontrado su orden en el modelo típico conventual de doble claustro con acceso y distribución desde cuerpo central. Ello ha significado encontrar una articulación física que permita integrar tanto vertical como horizontalmente ambos lados del conjunto, que se encuentran ordenados en torno a los dos patios existentes, con intervenciones diferenciadas de conservación estricta histórico-arquitectónica externa e interna en la Casa del Almirante, la rehabilitación con reformas interiores diversas de edificios anejos e intervenciones de obra nueva. 


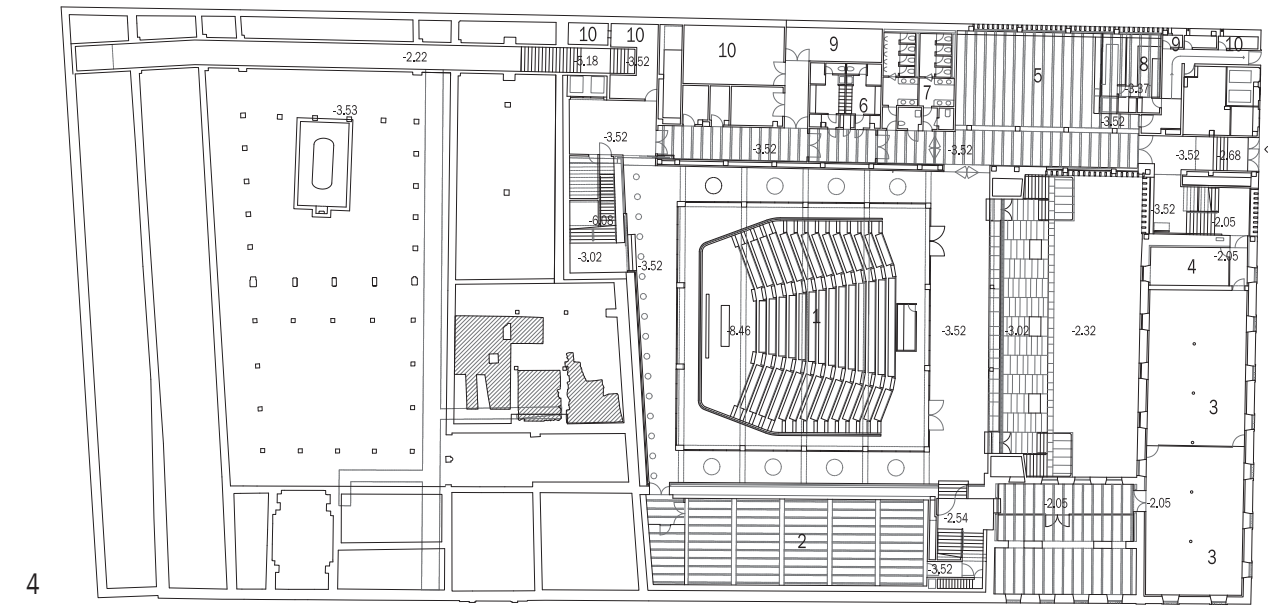

PLANTA SEMISÓTANO (COTAS ENTRE -3.52 Y -2.30m)
3. Plantas de entorno del proyecto en ejecución.

4. Plantas de semisótano del proyecto en ejecución.

5. Plantas principal del proyecto en ejecución.

6. Sección longitudinal del proyecto en ejecución. En ella se aprecian los patios existentes de la Casa del Almirante, el cuerpo central de acceso al doble claustro con la nueva escalera principal, el patio de los pabellones militares y el Aula Magna en semisótano.
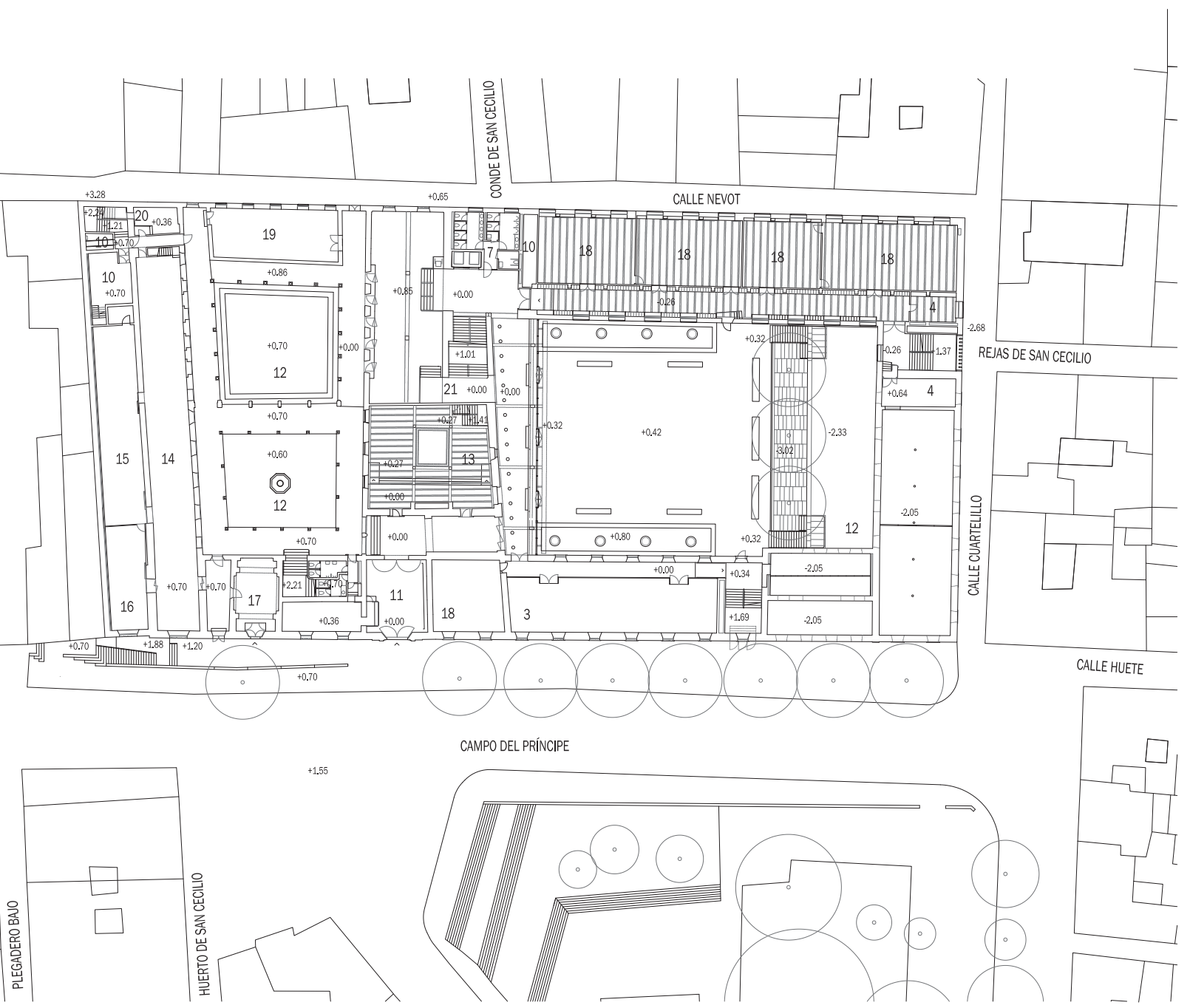

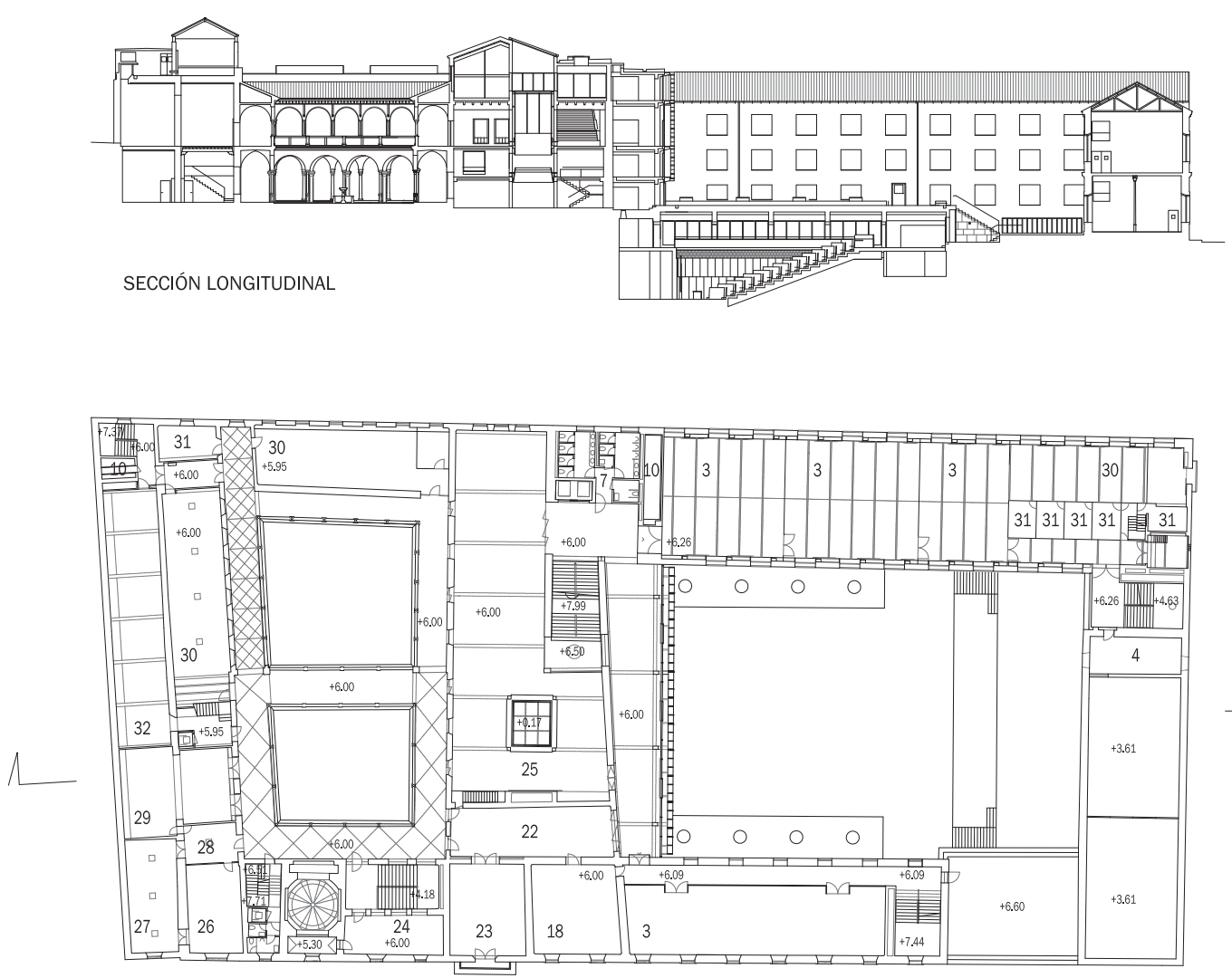

PLANTA PRINCIPAL $($ COTAS $+5.95,+6.09,+6.26 m)$

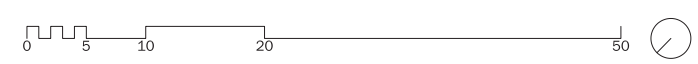

1. Aula magna, 2. Taller de maquetas, 3. Aula taller, 4. Tutoría, 5. Área de descanso, 6. Vestuarios, 7. Aseos, 8. Cocina, 9. Locales de mantenimiento, 10. Locales técnicos, 11. Zaguán, 12. Patio, 13. Secretaría, 14. Sala de lectura, 15. Depósito libros, 16. Archivo, 17. Publicaciones, 18. Aula teórica, 19. Reprografía, 20. Laboratorio fotografía, 21. Evacuación, 22. Vestíbulo, 23. Sala de profesores, 24. Delegación de alumnos, 25. Sala de profesores, 26. Despacho director, 27. Subdirección, 28. Secretario, 29. Sala de grados, 30. Departamento, 31. Despacho, 32. Laboratorio.

Solo desde el tratamiento tipológico estructural y constructivo coherente, el edificio se convertirá en una pieza arquitectónica válida.

El nuevo proyecto para el edificio propone una restauración del conjunto en el entendimiento de "restablecerlo a un estado de integridad que pudo no haber existido en un momento dado" como escribió Viollet Le Duc y que en este caso concreto es claro que nunca tuvo, o sólo tuvo en parte en alguna etapa concreta de su evolución. El proyecto alcanza la integridad arquitectónica con una intervención estructural de reconstrucción tipológica a partir de su consolidación como manzana urbana. Todo ello es posible, como diría Scarpa, desde la introducción de un nuevo elemento de vida al edificio: la Escuela de Arquitectura que le permite no solo seguir existiendo, sino convertirse en elemento de referencia monumental en el contexto urbano del barrio histórico.

La obra nueva se concentra en la reestructuración de la trasera del cuerpo central muy transformado, deteriorado y sin valor histórico o artístico alguno, que adquiere importancia estratégica por su posición baricéntrica, y la construcción del aula bajo rasante, aprovechando el des- nivel existente en el patio sur. Así, se define una fundamental conexión vertical, hoy inexistente, y se establece una relación horizontal entre ambos patios en todas las plantas, hoy sólo existente en el zaguán de entrada. De este modo los anillos de circulación de ambos patios se encuentran en el núcleo principal de comunicación vertical. Además, se crean otros dos núcleos de escaleras que resuelven la coordinación de niveles entre cuerpos contiguos y la circulación del conjunto (figuras 3 a 6).

El nuevo patio se remodela para adecuarlo a su nuevo papel de espacio abierto contemporáneo articulador de la nueva escuela, con una gran aula bajo rasante, para no consumir la ajustada edificabilidad, y un tratamiento pavimentado y ajardinado en dos niveles: superficial duro con materiales cerámicos sobre cubierta del auditorio y área ajardinada húmeda, a modo de gran arríate, que resuelve el escalón topográfico con arbolado de sombra que vincula ambos niveles.

La fachada a mediodía del patio recibe una circulación perimetral por medio de un nuevo corredor-galería que resuelve la medianera actualmente descubierta y rota por demolición del antiguo pabellón hospitalario, prote- 
N1_EL ESPACIO Y LA ENSEÑANZA DE LA ARQUUTTECTURA
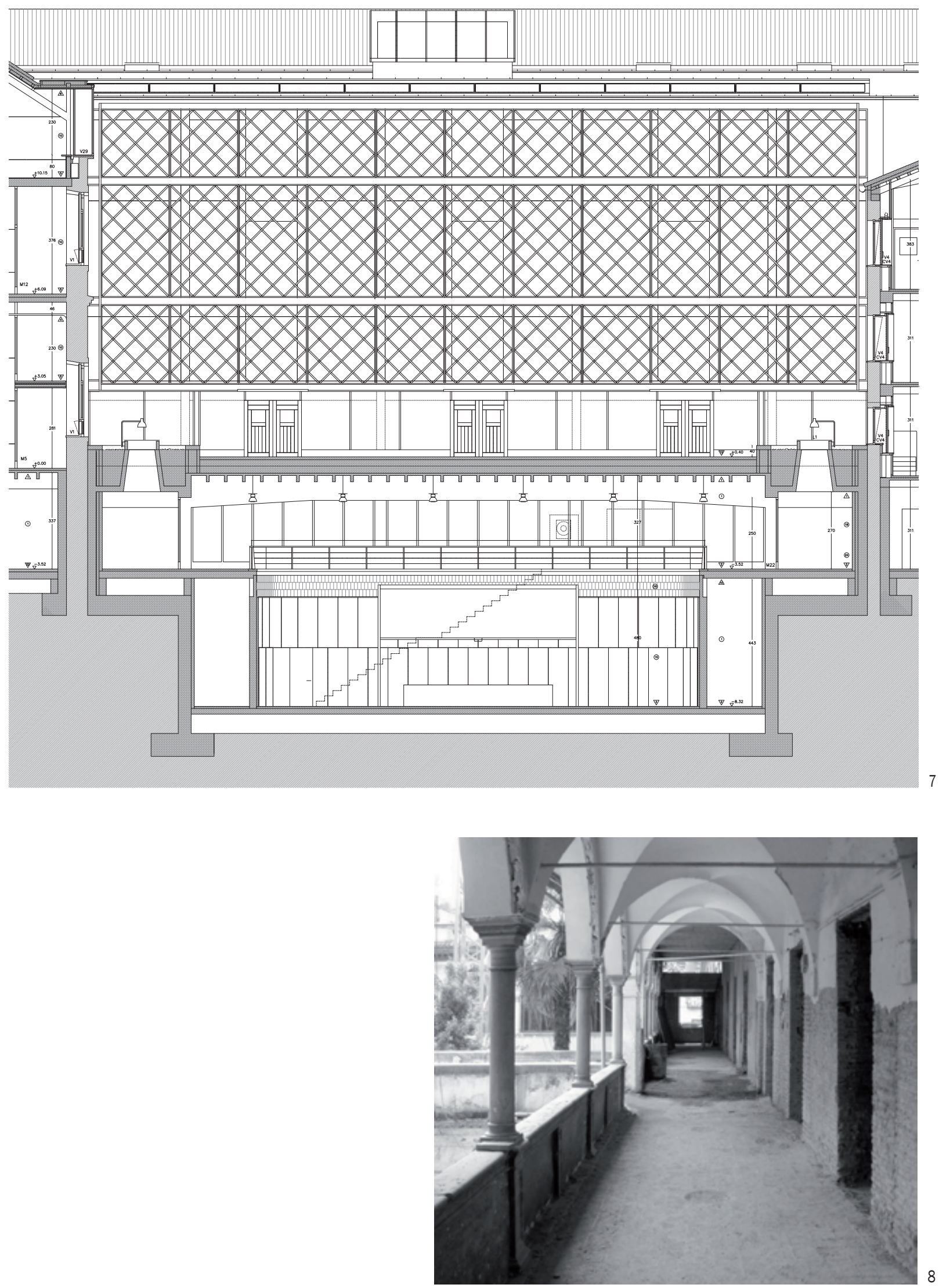
7. Sección transversal en la que se observa el Aula Magna en semisótano y la fachada con celosías al mediodía.

8. Imagen de una de las galerías abovedadas de la zona vinculada a la Casa del Almirante, en proceso de rehabilitación.

9. Imagen del lienzo de fachada de los pabellones militares, en proceso de rehabilitación.

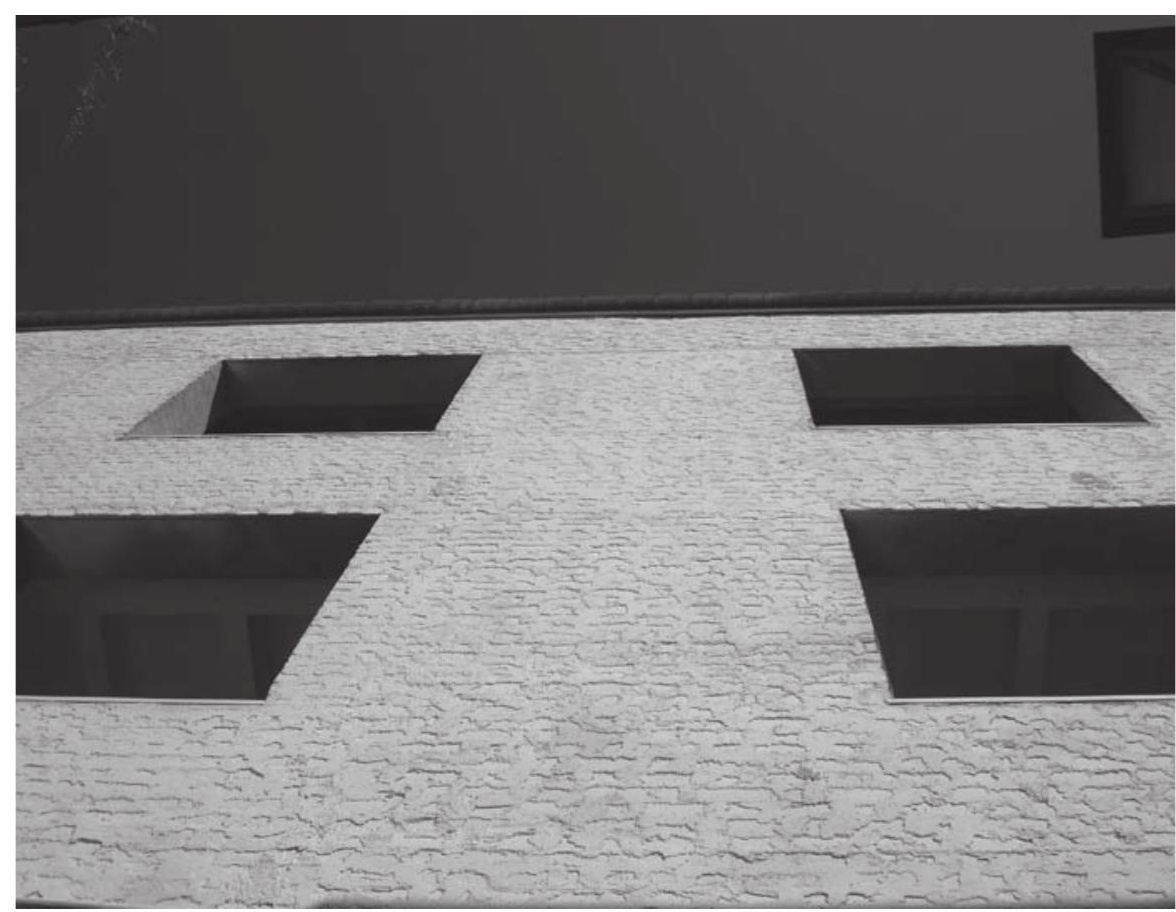

giéndose del soleamiento con una amplia celosía que servirá de guía a la vegetación, recogiendo con rigor contemporáneo la tradición de los patios andaluces de origen islámico (Corral del Carbón) (figura 7).

La conservación máxima se propone en el edificio de la antigua Casa del Almirante, (Siglo XIV) fundamentalmente en el patio antiguo y los cuerpos frontal y lateral norte que lo rodean, según se desprende de la información documental existente. Corresponde al nivel máximo de protección: Restauración con grado de conservación máxima, recuperación de partes desaparecidas y consolidación de áreas degradadas (figura 8).

Se conservan íntegramente fachadas y patio doblado de la fuente y del aljibe de esbeltas arcadas, recuperando su galería como espacio abierto, los frisos platerescos, los salones de espléndidos alfarjes mudéjares y artesonados, la capilla barroca y las pequeñas portadas.

El conjunto de pabellones hospitalarios novecentista, de digna arquitectura de anchos muros de fabrica de ladrillo, se reforman manteniendo su integridad física externa, conservando las fachadas, sustituyendo partes estructurales deterioradas o inadecuadas a la nueva función docente, manteniendo sin embargo por su interés y coherencia histórica, la actual disposición aditiva y heterogeneidad volumétrica (figura 9). El nuevo pabellón se mantiene, integrándolo físicamente en el edificio unitario. Ello implica eliminar su condición "aislada" relacionándolo con el conjunto como parte muy importante que es, tanto por su posición estratégica como por su uso. En este proyecto se reconfigura su estructura adecuando las dimensiones de sus pasillos y aulas eliminando las torres de escaleras que resultarían funcional y formalmente redundantes, así como las fachadas.

\section{FUNCIONALIDAD Y ORGANIZACIÓN ESPACIAL}

La escuela y su arquitectura es resultado de esta relación dialéctica entre espacios y funciones inicialmente definidas desde un programa docente ideal y que previsiblemente cambiará en el tiempo. El propio lugar como arquitectura será el mejor soporte de las características singulares y diferenciales de la Escuela de Granada en la búsqueda permanente del encuentro del saber y el lugar.

Basándonos en las premisas de capacidad, relación de superficie por alumno, en la nueva opción de la enseñanza en aula taller y en la división en los principales subusos: docente, administración, representación y servicios, se ha encontrado la distribución espacial idónea y acorde a las características del nuevo edificio.

Se propone una clara red cualificada de circulaciones, de primordial importancia en un edificio público y docente, por su visibilidad, legibilidad, orientación y capacidad para la transmisión no reglada de comunicación e información integradora. Los espacios de circulación no son sólo pasillos y escaleras sino también corredores, galerías, vestíbulos, salas de exposición, que como lugares públicos permiten la interacción abierta de alumnos, profesores, servicios, aulas, bibliotecas, salas de reunión, laboratorios y talleres. El resto del espacio, con una disposición flexible y capacidad para ajustarse a continuos cambios, se ha ordenado de acuerdo a las características del edificio distinguiendo ambientes más vinculados con el pasado y otros menos condicionados por la historia. 


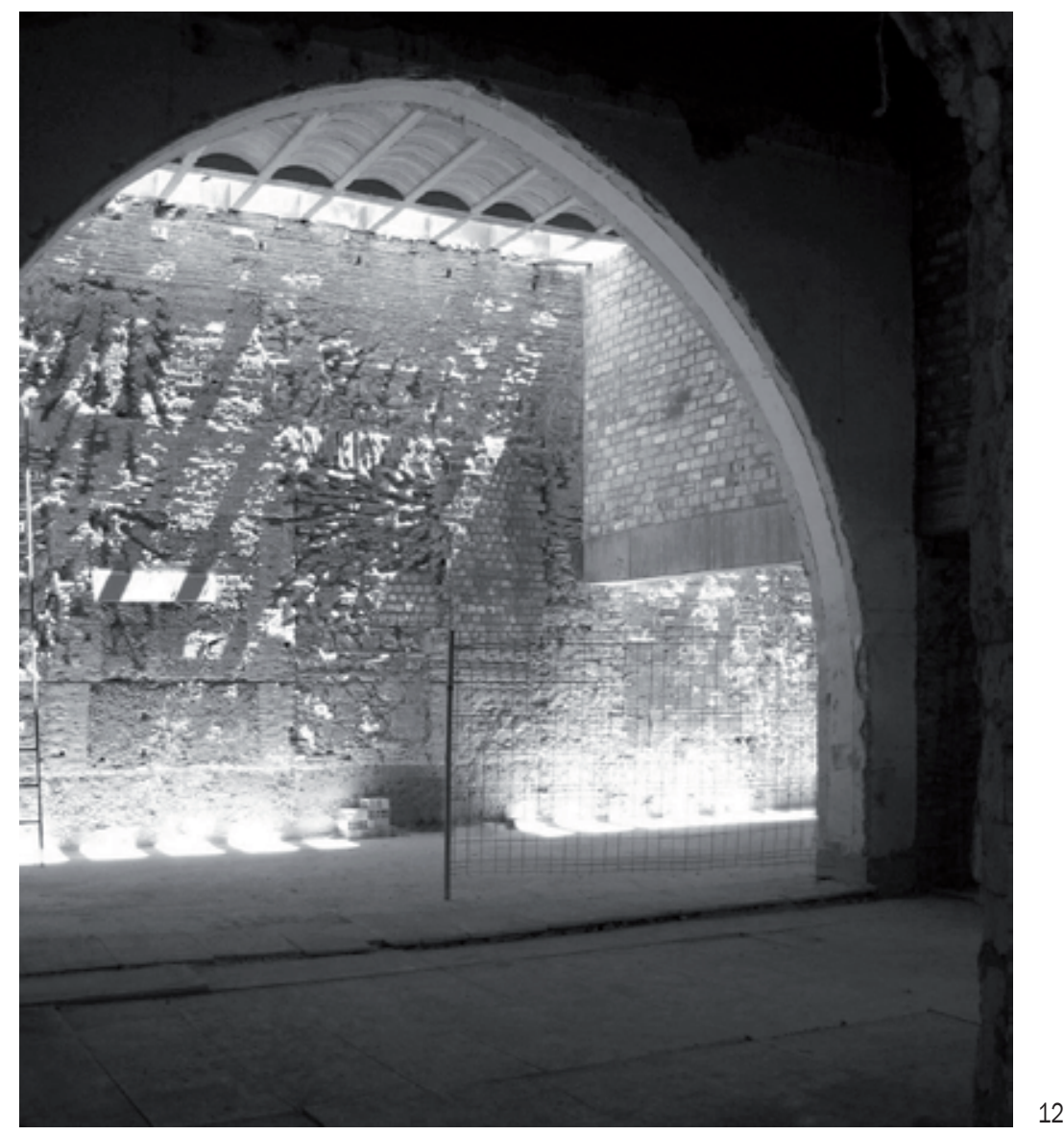

El uso docente, con el mayor consumo de superficie, se ha ubicado en el ala sur, alrededor del nuevo patio cuyos cuerpos ofrecen diafanidad y flexibilidad de uso para aulas teóricas y de taller. Los espacios representativos vinculados a la docencia, se distribuyen respondiendo a sus funciones en distintas áreas de la parte más antigua y restaurada del edificio, atendiendo a las características especiales de cada ámbito y a la adecuación de los usos a ellos (figura 10).

La biblioteca lo hace en el cuerpo norte de la "Casa del Almirante", en la planta baja abierta al patio, utilizando la crujía que aún dispone de la viguería de madera para las salas de lectura y la que no dispone de iluminación natural como área de almacén de libros. La ubicación de laboratorios, seminarios y despachos en los pisos superiores y resto de esta ala y cuerpo central, permite cualificar estos usos desde la dignidad de la antigua arquitectura bien conservada, alrededor del viejo patio (figura 11).

Los laboratorios de CAD y Urbanismo se ubican en el pabellón norte mientras que el resto, lo hacen en el piso superior del cuerpo central atendiendo a sus específicas necesidades (luz, ventilación, ruidos). En posición centrada en este cuerpo como centro de gravedad, bien conectado con la escalera principal, se coloca un área para sala de exposiciones abierta a ambos patios, como pieza clave de la actividad de la Escuela

Los espacios para administración se ubican en el cuerpo central del edificio ocupando los restos de la vieja casa nazarí, en una localización estratégica entre la entrada, el nuevo vestíbulo trasero y la escalera principal. La Dirección de la Escuela ocupa los espacios contiguos a la Capilla barroca, con fachada directa al Campo del Príncipe y próximo a la antigua escalera del patio. Junto a ella se encuentran igualmente los salones de grado, de profesores, etc., ocupando todo ello la parte más emblemática de la vieja Casa del Almirante (figura 12).

El Aula Magna se proyecta bajo rasante, centrada en el patio de mediodía, con acceso desde un amplio vestíbulo acristalado que, junto al bar, se abre directamente al nivel inferior del patio. Los pasillos que la circundan reciben iluminación cenital que en segundas luces iluminan el espacio del aula. Los pupitres se ordenan escalonados, orientándose hacia el centro del estrado. Este espacio, de estructura de hormigón visto potente y sencilla, que se extiende sobre los espacios vecinos, con la madera de pino como único revestimiento para sus paramentos, muebles 
13. Imágenes de las gradas del Aula Magna, aún sin cubrir por la cubierta ajardinada. Proceso de construcción.

14. Croquis de Víctor López Cotelo. Relación de los dos niveles del patio y del vestíbulo del aula Magna con el jardín.
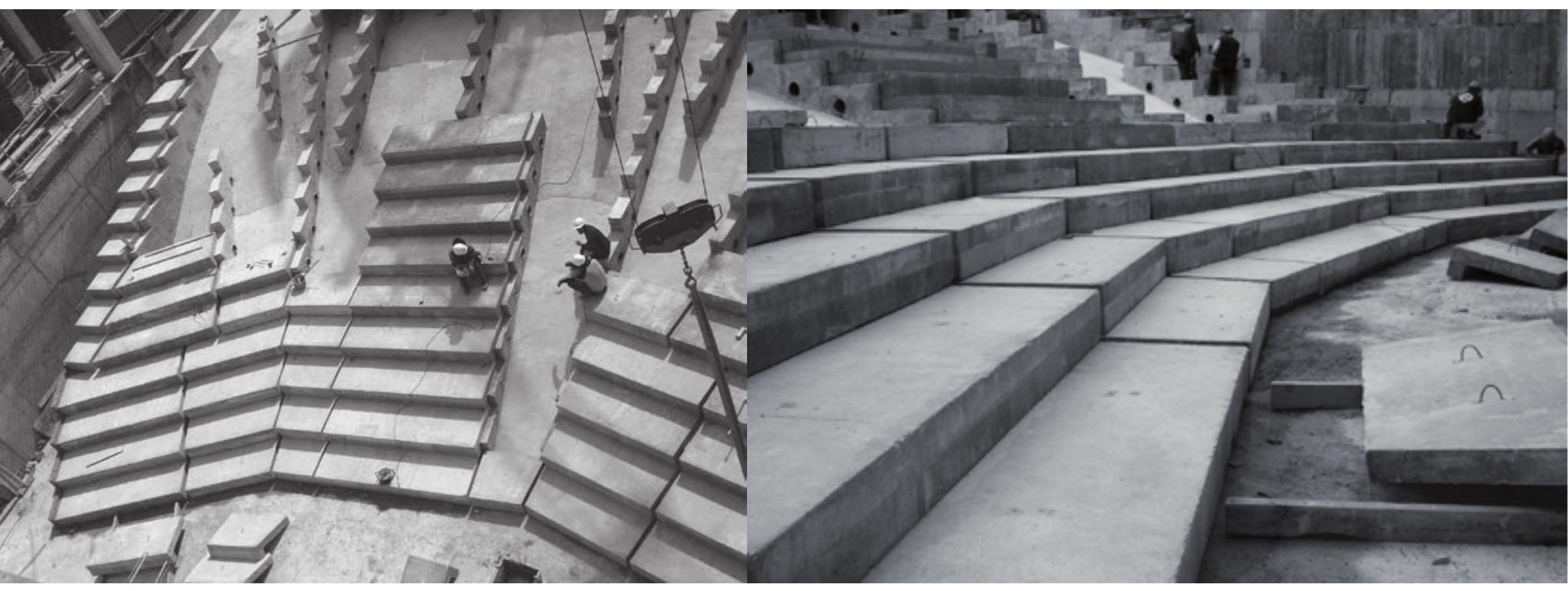

y pavimento, configura junto con las salas nobles de la Casa del Almirante el otro polo arquitectónico del edificio (figura 13).

La arquitectura de la obra nueva del Aula Magna, emerge al exterior configurando las galerías que a través de la celosía se abren al patio.

Esta distribución, ajustada al funcionamiento de la nueva Escuela y al programa de necesidades planteado, se adapta con flexibilidad y naturalidad a la estructura existente estableciendo una relación eficaz en su discreta austeridad con el carácter del edificio, sacando lo mejor de su singular condición física.

El nuevo edificio se constituye en "supermanzana" del barrio del Realejo en contraste con el histórico vacío urbano del Campo del Príncipe, abriéndose en toda su fachada a este espacio, mientras que en la trasera se adosa a la morfología del barrio a través de la estrecha calle Nevot.

Su modesta y austera fachada y portada se incorporan bien a la domesticidad del conjunto del barrio que parece dejar para las alturas en la cornisa del Mauror la monumentalidad y encierra tras sus muros un rico interior formado por dos amplios patios contrastados: uno renacentista, homogéneo y frondoso cerrado por galerías de arcos abovedados repetido como reflejo de espejo y el otro heterogéneo escalonado en dos niveles (figura 14), que deja ver en sus fachadas interiores las adiciones modernas y la visión contemporánea de la Escuela. Patios arbolados y ajardinados como corresponde a la tradición andaluza de la arquitectura introvertida, como pulmones microclimáticos y ambientales y orientadores internos del edificio. Por eso las galerías de circulación se abren a los patios como relojes del tiempo. La ciudad penetra por el zaguán de la puerta principal hacia los patios, en uno encuentra la expresión del pasado, en el otro nuestro tiempo, y en ambos se deja ver la actividad investigadora y docente de la nueva Escuela de Arquitectura.

El antiguo Hospital Militar encuentra nuevo impulso como Escuela de Arquitectura que vivifica y rejuvenece el barrio del Realejo. La Universidad de Granada agranda su reconocido prestigio al hacer visible a los pies de la ladera del Mauror una Escuela de Arquitectura singular que identifica la investigación arquitectónica con la ciudad de Granada. 


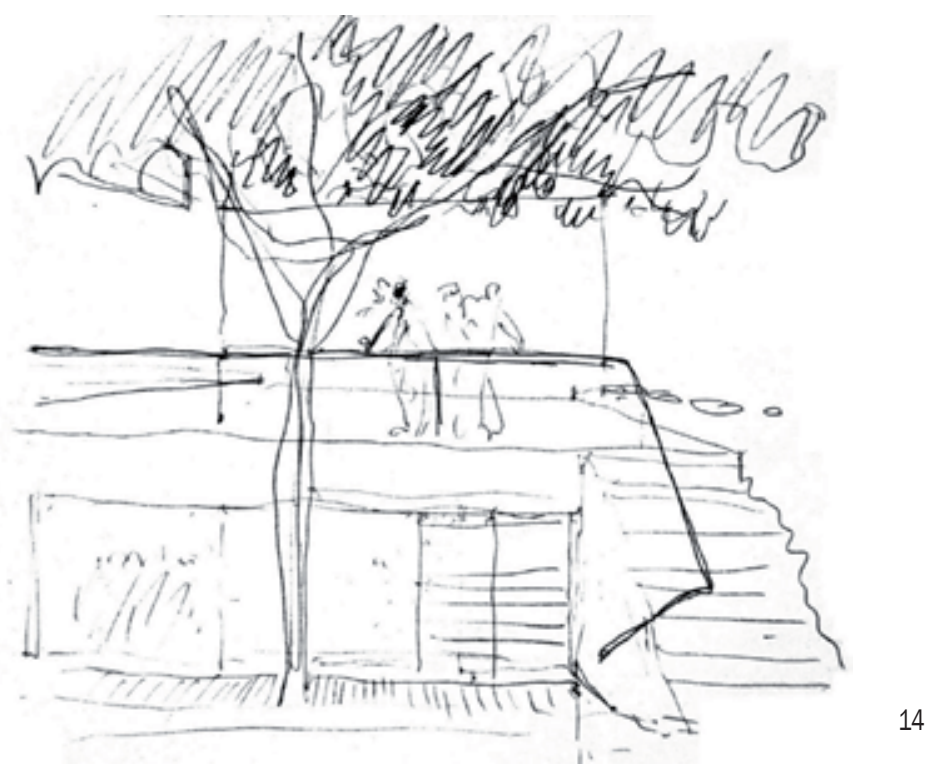

ESCUELA DE ARQUITECTURA DE GRANADA. Concurso: 1998. Proyecto: 2003. Inicio de obra: 2005 (en construcción). PROYECTO Y DIRECCIÓN DE OBRA: Víctor López Cotelo. ARQUITECTO COORDINADOR DE PROYECTO Y OBRA: Juan Uribarri Sánchez-Marco. APAREJADOR: José Antonio Valdés Moreno. CÁLCULO ESTRUCTURAS: Proyectos de Ingeniería y Arquitectura S.L. INSTALACIONES: Proyecto: JG Ingenieros. FOTOGRAFÍA: Estudio de Arquitectura Víctor López Cotelo

Víctor López Cotelo (Madrid, 1947). Arquitecto (1969), ETSA Universidad Politécnica de Madrid. Profesor de Proyectos Arquitectónicos 1983-86 ETSA Madrid. Catedrático de Proyectos Fakultät für Architektur Technische Universität München (1995). Ha impartido seminarios y conferencias en las Escuelas de Arquitectura de Berlín, Braunschweig, Clermont-Ferrand, Darmstadt, Lausanne, Graz y ETH Zurich entre otras. Finalista del premio "Mies van der Rohe" con la obra Biblioteca Pública de Zaragoza (1990), premio García Mercadal (1991), Premio COAM de Diseño por la intervención en el entorno del Monasterio de El Escorial (1996), premio Churriguera de Urbanismo de la Comunidad Autónoma de Madrid (1997), primer premio en el Concurso Internacional para la Escuela de Arquitectura de Granada (1998), premio en el Concurso para la nueva sede de los Archivos de la Filmoteca Española en Madrid (1999). En 2003 recibe el premio Manuel de la Dehesa de la VII Bienal de Arquitectura Española. En 2009, gran premio ENOR $4^{\text {a }}$ edición y Premio Salón IX edición. 